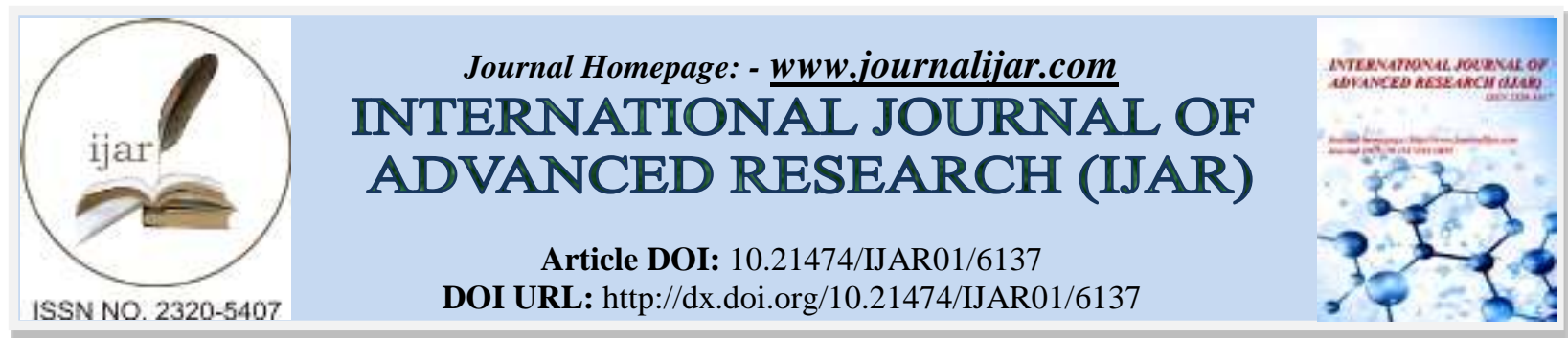

RESEARCH ARTICLE

\title{
INFLUENCE OF GROWTH CONDITIONS ON THE ELECTROCHROMIC EFFICIENCY AND THE ENERGY BAND GAP OF IRIDIUM OXIDE THIN FILMS.
}

\author{
Alaa A. Akl ${ }^{1,3}$, Salah M.M. Salman ${ }^{2,4}$ and Eman Kashita ${ }^{4}$. \\ 1. Physics Department, Faculty of Science, El-Minia University, El-Minia City, Egypt. \\ 2. Physics Department, Faculty of Science, Helwan University, Ain-Helwan-Egypt. \\ 3. Physics department, Faculty of Science, Ed Dawadmi, Shaqra University, Saudi Arabia. \\ 4. Educational Services, Qassim University, Ministry of High Education, Saudi Arabia.
}

\section{Manuscript Info}

(..........................

Manuscript History

Received: 22 October 2017

Final Accepted: 24 November 2017

Published: December 2017

Key words:-

Iridium Oxide, Electrochromic

efficiency, Spray Pyrolysis.

\section{Abstract}

In the present research, work has been focused on the efficiency of electrochromic properties and energy gap of Ir-oxide thin films as a function of preparative parameters. $\mathrm{IrO}_{2}$ thin films were deposited onto preheated indium tin oxide (ITO) coated glass substrates by cost effective chemical spray pyrolysis technique (SPT) at different substrate temperature $\left(\mathrm{T}_{\text {sub }}\right)$ and solution molarity (SM). Electrochromic characteristic of $\mathrm{IrO}_{2}$ thin films was studied in aqueous electrolyte of $0.1 \mathrm{M} \mathrm{H}_{2} \mathrm{SO}_{4}$. The optimum potential difference of coloration and bleaching state at +1.2 and $-1.2 \mathrm{~V}$, respectively. The results show that, the best value of electrochromic efficiency (CE) and the optical density difference $(\mathrm{DOD})_{\lambda=630 \mathrm{~nm}}$ were obtained at the conditions of preparation of $400^{\circ} \mathrm{C}$ and solution molarity of $0.01 \mathrm{M}$. $\mathrm{IrO}_{2}$ thin films were found to have a direct transition allowed. The value of energy gap $\left(E_{g}^{d}\right)$ for as-deposited, coloured and bleached states as a function of preparative parameters have been calculated. The obtained value of energy gape, $E_{g}^{d}$ as a function of film thickness was found to be remain constant of as-deposited, colored and bleached states while the changed with substrate temperature, $\mathrm{T}_{\text {sub. }}$. In addition, the fraction of crystalline volume of $\mathrm{IrO}_{2}$ was estimated of the investigated samples.

Copy Right, IJAR, 2017,. All rights reserved.

\section{Introduction:-}

The electrochromic process is defined as the material's ability to undergo electrochemical driven reversible light absorption changes [1,2]. Depending on the wavelengths absorbed, the phenomenon of electrochromic can be divided into two types: the visible type that occurs in the range of $350 \mathrm{~nm}$ to $850 \mathrm{~nm}$ and the other invisible type that occurs in the range smaller than $350 \mathrm{~nm}$ and in the range greater than $850 \mathrm{~nm}$. The materials that possess this characteristic are the metal transition oxides such as tungsten, nickel, vanadium, etc., which are divided into two basic types of polarization, one of which is anodic and the other is cathodic. Iridium oxide $\left(\mathrm{IrO}_{2}\right)$ is one of them, an anodic electrochromic material, which is able to change the color from transparent to bluish-black in positive potential and is bleached inversely when negative potential is applied [3]. The study of the physical properties of iridium oxide is important for many applications such as the optical information storage [4], catalyst for the 
development of $\mathrm{O}_{2}$ [5], microelectronic devices and $\mathrm{pH}$ sensors. It is also used as a promising electrochromic material because it has the following properties: fast coloring and bleaching many times and in very small time $(<50$ $\mathrm{ms}$ ), with good memory in open circle and reverse circuit (>90\%) [6]. It is also highly stable material no change with repeated use ( 50 cycles) and relatively sharp threshold voltage [7]. Thin films of iridium oxide have been prepared using various techniques including thermal oxidation [8], anode oxidation [9], RF- sputtering [10], electrodepositing [11], sol-gel processing [12] and spray pyrolysis [13-15]. In the previous paper, thin films of Iroxide were prepared on a heated glass substrate using iridium chloride spraying method $\left(\mathrm{IrCl}_{3} \cdot 3 \mathrm{H}_{2} \mathrm{O}\right)$ to obtain a single phase with varying degrees of crystallization [14]. X-ray diffraction has been used to characterize the structure as well as features of microstructural parameters. Investigations lead to a two-phase model characterized by nano-crystallite size $(15 \mathrm{~nm})$ dispersed in an amorphous matrix in films deposited on hot substrates at $\mathrm{T}_{\text {sub }} \geq 400^{\circ} \mathrm{C}$. The dark conductivity at room temperature and activation energy of the $\mathrm{IrO}_{2}$ crystalline films were found to be $1.68 \times 10^{-3} \Omega^{-1} \cdot \mathrm{cm}^{-1}$ and $0.21 \mathrm{eV}$, respectively. In addition, the optical properties of $\mathrm{IrO}_{2}$ thin films were studied [15]. The effects of substrate temperature $\left(\mathrm{T}_{\text {sub }}\right)$ and solution molarity $(\mathrm{SM})$ on optical constants were examined. The results obtained showed that the value of the refractive index is based on chemical composition as well as on the stoichiometry of films. The values obtained from the high-frequency dielectric constant shall be through two procedures in the range of 2.8-3.9 and 3.3.4.6 on the respective ranges of the $\mathrm{T}_{\text {sub }}$ and the SM, respectively. The obtained fabricated samples are characterized by direct transition allowed. Therefore, it is expected that the electrochromic properties and the energy gap of Ir-oxide films may also show interesting behavior with preparative parameters. The objectives of this study are:

1. Thin films of Ir-oxide of various thicknesses were deposited by varying concentration on the ITO coated glass substrates at different $\mathrm{T}_{\text {sub. }}$.

2-The effect of $\mathrm{T}_{\text {sub }}$ and the concentration of the solution on electrochromic behavior (EC) properties are investigated and discussed

3. Identify energy gaps for $\mathrm{IrO}_{2}$ in their bleached and colored states

\section{Experimental work:-}

\subsection{Preparation of iridium oxide single phase}

Thin film of $\mathrm{IrO}_{2}$ was deposited by a SPT of aqueous solution of trihydrated iridium chloride $\left(\mathrm{IrCl}_{3} .3 \mathrm{H}_{2} \mathrm{O}\right)$ into ITOcoated glass substrates. The solution was passed through pneumatic sprays with a diameter of $0.7 \mathrm{~mm}$ nozzle. The nitrogen flow rate remained constant at $80 \mathrm{~mL} / \mathrm{hr}$. The temperature controller was used to measure the $\mathrm{T}_{\text {sub }}$ and control the heat-resistant heater. In order to explore the effect ranging from 350 to $500^{\circ} \mathrm{C}$ used to prepare these films. The solution was sprayed at different concentrations $(0.005-0.03 \mathrm{M})$ through a glass nozzle using air as a carrier. In order to obtain uniform thin films, the height of the spray nozzle, the deposition time and the spray solution rate were remain constant during deposition at $25 \mathrm{~cm}, 10 \mathrm{~min}$ and $5 \mathrm{~cm}^{3} / \mathrm{min}$, respectively.

To examine samples of $\mathrm{IrO}_{2}$ films deposited on the ITO coated glass substrates and have annealed at $600^{\circ} \mathrm{C}$ for $2 \mathrm{hr}$. The thickness of the film of the as-deposited and annealed was measured using the mechanical stylus method (MSM) (Sloan-Dektak, Model 11A) [16].

\subsection{Electrochromic properties}

Optical transmittance was recorded in different states (colored and bleached) of the prepared samples at a wavelength range of $300 \mathrm{~nm}$ to $900 \mathrm{~nm}$ using Shimadzu of 3101 PC: UV VIS-NIR double beam spectrophotometer. The EC properties of Ir-oxide thin films which prepared onto ITO-coated glass substrates at different preparation conditions were investigated. These films have been used as working electrodes in a three electrodes electrochemical cell containing $0.1 \mathrm{M}, \mathrm{H}_{2} \mathrm{SO}_{4}$ aqueous solution. The electrode is made of platinum sheet and the saturated calomel electrode $(\mathrm{SCE})$ is used as a reference electrode $(\mathrm{Ag} / \mathrm{AgCl})$.

\section{Results and discussion:-}

\subsection{Film thickness measurements}

The thickness of the film was measured for all samples that were prepared in different $T_{\text {sub }}$ by mechanical stylus method (MSM). The thickness of the deposited films was found to vary from 120 to $265 \mathrm{~nm}$, where the $\mathrm{T}_{\text {sub }}$ increased from 350 to $500^{\circ} \mathrm{C}$, while the film thickness of the annealed samples varied from 105 to $230 \mathrm{~nm}$, respectively. Figure 1 shows the film thickness as a function of $\mathrm{T}_{\text {sub }}$ of as-deposited and annealed samples.

\section{Figure (1)}

It is observed that the reduction in film thickness with the $\mathrm{T}_{\text {sub }}$ may be due to the expulsion of water molecules and chlorine ions from the film. However, this decrement in the film thickness does not exactly inversely proportional 
to the $\mathrm{T}_{\text {sub }}$. This is due to the evaporation rate of the primary product is an increase in the rise in $\mathrm{T}_{\text {sub }}$, resulting in mass transport contraction towards the substrates, resulting in a decrease in film thickness [17]. Each data point is the average of five measurements taken at different locations on the surface of the film, and the calculated error in the thickness of the film is found to be $\pm 5 \%$

Figure 2 shows the film thickness as a function of the concentration of the solution sprayed for as-deposited and annealing samples.

\section{Figure (2)}

The observed reduction in film thickness with annealing may be due to the expulsion of water molecules and chlorine from the film. Moreover, the increase in the film thickness is not exactly directly proportional to the molarity solution. This may be due to the change in the sedimentation efficiency of the SPT, which may result from a reduction in mass transport to the substrate and due to the gas convection, thus pushing the precursor droplets away.

\subsection{Crystalline volume fraction}

The crystalline volume fraction was estimated by analyzing the optical reflectivity spectra in the ultraviolet region [18]. The fraction of crystalline volume, $X_{C}$ is defined by the following formula;

$$
X_{C}=\left(\frac{n_{C}-n_{A}}{n_{S}-n_{A}}\right)
$$

Where, $n_{C}, n_{A}$ and $n_{S}$ the refractive indices are complex for crystalline, amorphous and single crystalline of IrO ${ }_{2}$, respectively [15]. The fraction of the crystalline $\mathrm{IrO}_{2}$ was obtained by the incorporation of calculated reflectivity spectra into experimental reflectivity spectra. The crystalline volume fraction, $\boldsymbol{X}_{\boldsymbol{C}}$, was found in the range of 0.22 to 0.08 for crystalline $\mathrm{IrO}_{2}$ films as the $\mathrm{T}_{\text {sub }}$ increases from 350 to $500^{\circ} \mathrm{C}$, respectively. It can be observed that, the increase in the $\mathrm{T}_{\text {sub }}$ stimulates the change in the amorphous-crystalline transformation, indicating a decrease in $\boldsymbol{X}_{\boldsymbol{C}}$ in the samples that have been investigated. Because, at temperature increases, increases the kinetic energy of ions, resulting in the agglomerate destruction of crystal. Thus, full grain growth does not occur, which reduces the crystal formation of $\mathrm{IrO}_{2}$. This fact is related to the crystallization of materials for high $\mathrm{T}_{\text {sub }}$ [19]. While the crystalline volume fraction, $\boldsymbol{X}_{\boldsymbol{C}}$, of the $\mathrm{IrO}_{2}$ with a different SM of $0.005-0.3 \mathrm{M}$, the scale was slightly changed from $0.48-0.55$. This means that no changes were observed in the crystallization of $\mathrm{IrO}_{2}$ for films deposited in different $\mathrm{SM}$, because this concentration is suitable for the crystal growing on the substrate due to the appropriate mobility of the ions. We can conclude that the spraying temperature has a clear effect on the crystallization degree of the $\mathrm{IrO}_{2}$, while it is independent of the film thickness.

\subsection{Electrochromic characterization \\ 3.3.1. Optical transmittance studies}

When the external voltage $\pm 1.2 \mathrm{~V}$ is applied on the reference electrode between the working and the counter electrode, then the bluish-black coloration is observed within a few seconds $(5 \mathrm{sec})$. Samples were taken from the cell and provided to measure optical transmittance. The conductive ITO layer that coated glass substrate is the reference electrode for measuring the electrochromic behavior of the samples and thus measured the optical transmittance at the same time. These samples were also bleached at $-1.2 \mathrm{~V}$ in the cell and a similar procedure was performed.

Figure 3 (a-d) shows the spectral transmittance of $\mathrm{IrO}_{2}$ films deposited at different substrate temperature in colored and bleached states.

Figure 3(a-d)

The overall transmittance decreases after coloring, indicating absorption of light due to the formation of color centers. It is clear that, as the $\mathrm{T}_{\text {sub }}$ increases, the higher of the electrochromic performance and then the deterioration of the films grown in $\mathrm{T}_{\text {sub }}>350^{\circ} \mathrm{C}$, where the crystals of $\mathrm{IrO}_{2}$ began to grow [12]. Since the electrochromic process occurs by inserting and removing the protons and electrons from the electrolyte, which is coordinated with the crystal lattice of $\mathrm{IrO}_{2}$. 
The following coloring and bleaching process is proposed to spray deposited $\mathrm{IrO}_{2}$ films [20,21]:

$\mathrm{Ir}(\mathrm{OH})_{3}-\mathrm{H}^{+}-\mathrm{e}^{-} \stackrel{\text { coloured/ bleached }}{\longleftrightarrow} \mathrm{IrO}_{2} . \mathrm{H}_{2} \mathrm{O}$

or

$\mathrm{Ir}(\mathrm{OH})_{3}+\mathrm{OH}^{-}-\mathrm{e}^{-} \stackrel{\text { coloured/ bleached }}{\longleftrightarrow} \mathrm{IrO}_{2} \cdot 2 \mathrm{H}_{2} \mathrm{O}$

According to the mechanism in the sprayed Ir-oxide film is given by equation ( 2 or 3 ), when the external voltage of +1.2 volts was applied, and the insertion of $\mathrm{H}^{+}$or $\mathrm{OH}^{-}$ions to iridium sites $\left(\mathrm{Ir}^{+3}\right)$, causing the coloration while in negative potential (-1.2 volts), the extraction of $\mathrm{H}^{+}$or $\mathrm{OH}^{-}$ions from iridium sites $\left(\mathrm{Ir}^{+4}\right)$ causing bleaching state $[12,13,22,23]$. Figure 4(a-d) shows the optical transmittance spectrum of the colored and bleached condition of $\mathrm{IrO}_{2}$ films as a function of SM.

\section{Figure 4(a-d)}

Clearly, the value of transmittance decreases when the solution molarity is increased, and a higher value is observed at $0.005 \mathrm{M}$. $\mathrm{IrO}_{2}$ film transmittance was recorded at $\lambda=630 \mathrm{~nm}$ for colored, bleached and as-deposited (Table 2). It is noted that the value of transmittance in the bleached state is higher than the as-deposited one $(\approx 8 \%)$. This may be due to the permanent binding of some ions initially incorporated into the host lattice, which is difficult for the dendritic [21].

\subsubsection{Evaluation of optical absorption}

When the light is incident on the surface of a thin film, partially reflected $(\boldsymbol{R})$, partially transmitted $(\boldsymbol{T})$ and partially absorbed $(\boldsymbol{A})$. The absorption part is measured by absorbance, and is related to the optical density $(\boldsymbol{D})$ by:

$$
A=\operatorname{Ln}\left(\frac{I_{o}}{I}\right)=2.303 \log \left(\frac{I_{o}}{I}\right)=2.303 D
$$

Absorption $(\boldsymbol{A})$ is calculated as follows;

$$
T+R+A=1
$$

The transmittance $(\boldsymbol{T})$, reflectance $(\boldsymbol{R})$, absorbance $(\boldsymbol{A})$ and optical density (D) for $\mathrm{IrO}_{2}$ films at $\lambda=630 \mathrm{~nm}$ of each states are shown in Table 1. Equations 4 and 5 give values $\boldsymbol{A}$ and $\boldsymbol{D}$ for each electrochromic behavior as a function of $\mathrm{T}_{\text {sub }}$ (Table 1). The results showed that the decrease in absorptivity of all states could be attributed either to the growth of grains associated with high temperature, or to increased crystallization or both.

Table 2 shows the values of $\boldsymbol{T}, \boldsymbol{R}, \boldsymbol{A}$ and $\boldsymbol{D}$ of $\mathrm{IrO}_{2}$ films at $\lambda=630 \mathrm{~nm}$ for each states as a function of SM. Clearly, the $\boldsymbol{A}$ and $\boldsymbol{D}$ values were increased with the increased concentration of the solution. The result is that the values of $\boldsymbol{A}$ and $\boldsymbol{D}$ depend on the thickness of the film. This synchronize increase in $\boldsymbol{A}$ and $\boldsymbol{D}$ may be due to a change in the deposition amount of iridium oxide spray particles. The difference was related to the structural characteristics of the films. Consequently, these results may indicate that different SM of spray films have a significant effect on the absorbance and optical density of the iridium oxide.

\subsubsection{Evaluation of photopic contrast}

The photopic contrast ratio was calculated at $630 \mathrm{~nm}$ of $\mathrm{IrO}_{2}$ films using the relation;

$$
\text { Contrast ratio }=\left(\boldsymbol{T}_{b} / \boldsymbol{T}_{c}\right)_{\lambda=630 \mathrm{~mm}} \quad(6)
$$

Photopic contrast ratio values as a function listed in Table 3. It is clear that the photopic ratio values drop slightly from 1.318 to 1.070 when increasing the $\mathrm{T}_{\text {sub }}$ of $350-500^{\circ} \mathrm{C}$, respectively. The decrement contrast ratio may be due to the decrease of film thickness and improved crystallization, resulting in lower optical absorption. Also, the contrast ratio values are recorded as a function of SM in Table 4. Note that the contrast ratio remained almost constant with the increase of SM. The difference may be slight due to film thickness and surface roughness. This value is in good agreement with the reported value of the $\mathrm{IrO}_{2}$ film prepared by spray pyrolysis [20].

\subsubsection{Evaluation of colouration efficiency}

The efficiency of coloration $(\boldsymbol{E C})$ is an important parameter for the characterization of electrochromic devices, and is estimated as the optical density difference (DOD) divided by the injection charge in the unit area of the film. The DOD of the film is the definition of transmittance difference at $630 \mathrm{~nm}$ between bleached and colored states according to the Law of Beer-Lambert [24]. 
$\mathrm{DOD}=\operatorname{Ln}\left(\frac{T_{b}}{T_{c}}\right)_{\lambda=630 \mathrm{~nm}}$

Where $T_{b}$ and $T_{c}$ are the transmittance of bleached and colored states, respectively. The bleached state is defined by the end of a periodic potential in $+1.2 \mathrm{~V}$, which restores the current density to its original state. The colored state is at the end of the coloring process in $-1.2 \mathrm{~V}$. The EC was calculated using the relationship;

$\mathrm{CE}=\mathrm{DOD} / \mathrm{Q}_{\mathrm{i}} \quad$ at $630 \mathrm{~nm}$

Where $\mathrm{Q}_{\mathrm{i}}$ is the amount of charges intercalated in the sample, which was estimated by integrating the area under the current density curve versus time. The values of DOD, $\mathrm{Q}_{\mathrm{i}}$ and $\mathrm{CE}$ are recorded as a function of $\mathrm{T}_{\text {sub }}$ in Table 3. Note that $\mathrm{CE}$, also called as electrochromic efficiency (EE) depends strongly on sample preparation. In order to optimize the temperature setting, the electrochromic parameters were achieved by following the difference of optical density as well as CE for different temperatures. From the obtained data, the maximum values of DOD and CE (32.36 $\mathrm{cm}^{2} / \mathrm{C}$ ) in the $\mathrm{T}_{\text {sub }}=400^{\circ} \mathrm{C}$. Therefore, this temperature is the optimum spray temperature. Results confirm the results of other works $[13,25]$. Also, the CE was calculated as a function SM. Table 4 gives DOD, Qi and CE values of deposited films at different concentration. The results showed that at SM of $0.01 \mathrm{M}$, it was found that the maximum value of CE is $20.98 \mathrm{~cm}^{2} / \mathrm{C}$. This value is in good agreement with the CE value reported by other researchers such as Kawar et al. [20] and Patel et al. [21]. In both cases of study, optimal substrate temperature and concentration were found to deposit thin $\mathrm{IrO}_{2}$ films suitable for electrochromic devices to be $400^{\circ} \mathrm{C}$ and $0.01 \mathrm{M}$, respectively.

\subsubsection{Evaluation of energy gap}

The absorbance spectrum of a material submitted to an electromagnetic radiation is determined by the wavelengths corresponding to allowed transitions between occupied and unoccupied electronic energetic levels. In its neutral state, allowed transitions are related to the energetic difference between the valence band and conduction band, defined as the band gap of the material. Oxidation of an electrochromic material produces absorbent species, radical cations (polarons) or dications (bipolarons) and the subsequent new energetic levels, allowing new electronic transitions and therefore changing the absorption spectra. In the same way, reduction processes gradually eliminate these levels until the distribution returns to that of the initial neutral state. Absorption spectrum of an electrochromic material is then reversibly controlled by its oxidation state. The energy gaps $E_{g}^{d}$ and the absorption coefficient $\alpha$ are correlated according to the following equation [26]:

$$
(\alpha h v)^{2}=K\left(h v-E_{g}^{d}\right)
$$

Where $K$ is a constant independent of the photon energy, $h v$ is the incident photon energy and $E_{g}^{d}$ is the direct allowed energy gap. The optical energy gap, $E_{g}^{d}$, for direct allowed transitions can be evaluated from the plot of $(\alpha h v)^{2}$ versus photon energy $(h v)$. The Tauc plot is expected to exhibit linear behavior in the high energy region, corresponding to strong absorption. The $E_{g}^{d}$ of the film is evaluated by fitting the linear region of the plot to zero.

\section{Figure (5)}

Fig. (5) shows the variation of $E_{g}^{d}$ of the as-deposited, coloured and bleached states at different $\mathrm{T}_{\text {sub. }}$ It is clear that, the $\mathrm{T}_{\text {sub }}$ have pronounce effect on the value of $E_{g}^{d}$. When $\mathrm{T}_{\text {sub }}$ increases, the amplitude of atomic vibrations increases, leading to large of interatomic spaces. The interaction between the lattice phonons and the free electrons and holes will also affect the band gap to a smaller extent. The relationship between band gap energy and temperature can be described by Varshni's empirical expression [27];

$$
E_{g}(T)=E_{g}(0)-\frac{\alpha T^{2}}{T+\beta}
$$

Where $\boldsymbol{\alpha}$ and $\boldsymbol{\beta}$ are constants and $\boldsymbol{E}_{\boldsymbol{g}}(\boldsymbol{0})$ is the energy gap at zero temperature. The energy gap in a regular semiconductor crystal is fixed owing to continuous energy states. While in an oxidation states (coloured and bleached states), band gap is size dependent and can be altered to produce a range of energies between the highest occupied molecular orbital and the lowest unoccupied molecular orbital. Furthermore, the chemical composition and 
degree of crystallinity of the coating film were increases by increasing the number of crystallites rather than an increase of their size, which associated with electrons scattering and caused decrease in the energy gap values [15]. This may explain the observed gradual decrease in energy gap with the absence of a sharp amorphous-crystalline transformation accompanied by a sharp change in the energy gap values. Our value of $E_{g}^{d}$ is in agreement well with results early reported by Kawar et al. [20].

The optical energy gap, $E_{g}^{d}$, for direct allowed transition as a function of SM in different colouration states can be obtained from equation (9). The obtained values of $E_{g}^{d}$ for as-deposited, coloured and bleached states as a function of SM are shown in Fig.(6).

\section{Figure (6)}

It is can be seen that, the value of $E_{g}^{d}$ for as-deposited $\mathrm{IrO}_{2}$ films was remains constant with increase of the solution concentrations. For colouration and bleached states, $E_{g}^{d}$ decreases than as-deposited and keeps constant with higher concentrations. The slight variation may be due to insertion number of hydrogen ions in $\mathrm{IrO}_{2}$ films which produce localized states in the band gap. The presence of high concentration of localized states in the band structure is responsible for low values of $E_{g}^{d}$ in the electrochromic behaviour. Furthermore, the slightly decrement in energy gap may be due to an increase in the film thickness, as well as crystallinity and hence carrier concentration, which stem from ionization of defect and change in mobility of charge carriers [28].

\subsubsection{Switching time measurements}

In order to examine the switching time, the transmittance at $\lambda=630 \mathrm{~nm}$, for a film deposited at optimum $\mathrm{T}_{\text {sub }}$, was measured after the $160^{\text {th }}$ cycle. The applied potential was switched between -1.2 and $+1.2 \mathrm{~V}$ and the definition of the switching time was the time for the charge of the $\mathrm{IrO}_{2}$ films to be injected/extracted at $630 \mathrm{~nm}$.

\section{Figure (7)}

Fig.(7) shows the time response as a function of the transmittance. It is obvious that the bleaching response time, $13 \mathrm{~s}$, is about three times of the colouring one, 5s. It can be concluded that the switching time during the bleaching process is faster than that of colouring one. The evidence shows that $\mathrm{IrO}_{2}$ films have quick response time and charged immediately within $5 \mathrm{~s}$ to this reactive surface properly.

\section{Conclusions:-}

The increment of $\mathrm{T}_{\text {sub }}$ of the prepared films showed decrement in film thickness. This is due to an increase in the evaporation rate of initial product, leading to diminished mass transport towards the substrates. Also, the observed decrement in film thickness upon annealing may be due to expulsion of water molecule and chlorine ions from the film. Furthermore, the increase in film thickness is not exactly directly proportional to the SM.

When $\mathrm{T}_{\text {sub }}$ increases, the change in the amorphous-crystalline transition is occurs, leading to decrease in the crystalline volume fraction of crystalline $\mathrm{IrO}_{2}$ films. Owing, the mobility of ions increases, leading to crystal agglomerate destruction. Thus, complete grain growth does not occurs. The crystalline volume fraction was slightly changed when SM increases. This means that no variation in crystallite of $\mathrm{IrO}_{2}$ was observed for films deposited at different SM since this concentration is appropriate for crystal growing on the substrate due to the suitable mobility of ions.

The EC process is occurs when applied an external voltage of $\pm 1.2 \mathrm{~V}$, then bluish-black colouration is observed. The $\mathrm{IrO}_{2}$ thin films exhibit anodic electrochromism and fast response in $0.1 \mathrm{M} \mathrm{H}_{2} \mathrm{SO}_{4}$ electrolyte, $5 \mathrm{~s}$ for colouration and $13 \mathrm{~s}$ for bleaching. This is due to the insertion and removal of protons and electrons from water of crystallization, which is coordinated with $\mathrm{IrO}_{2}$ lattice. The behavior of $\mathrm{EC}$ as a function of $\mathrm{T}_{\text {sub }}$ showed that, the maximum value of the $\mathrm{OD}$ and $\mathrm{CE}$ were obtained at $400^{\circ} \mathrm{C}$ and $0.01 \mathrm{M}$. The decrements of electrochromic activity of sprayed $\mathrm{IrO}_{2}$ may be due to the degree of crystallinity. Therefore, this temperature and solution concentration is the optimum preparation conditions. The change in coloration to bleaching state upon polarization in sprayed Ir-oxide film is due 
to well-known fact that $\operatorname{Ir}^{3+} \leftrightarrow \operatorname{Ir}^{4+}$ intervalance charge transfer reaction. Also, the stability of films was tested by running several times colour/bleached up to about 160 cycles.

The band gap energy of $\mathrm{IrO}_{2}$ tends to decrease with increasing $\mathrm{T}_{\text {sub }}$. This is due to, the amplitude of atomic vibrations increase which leads to a larger interatomic spacing. The interaction between the phonons and the free electrons and holes will also affect the band gap to a smaller extent. Furthermore, it can be possible transformation from semi-conducting phase to metallic one. This transition is conceived to be due to the change in oxidation state of iridium as a result of which the Fermi energy level, $E_{f}$, crosses the conduction band edge $E_{c}$.

Table 1:- Values of the transmittance, $\boldsymbol{T}$, reflectance, $\boldsymbol{R}$, absorbance, $\boldsymbol{A}$ and optical density, $\boldsymbol{D}$ obtained from the optical spectrum at $\lambda=630 \mathrm{~nm}$ for electrochromic behaviour of $\mathrm{IrO}_{2}$ as a function of substrate temperature.

\begin{tabular}{|l|l|l|l|l|l|l|l|l|l|l|l|l|}
\hline \multirow{2}{*}{$\mathbf{T}_{\text {sub }}\left({ }^{\circ} \mathbf{C}\right)$} & \multicolumn{4}{|l|}{ As-deposited [15] } & \multicolumn{4}{l|}{ Coloured state } & \multicolumn{3}{l|}{ Bleached state } \\
\cline { 2 - 13 } & $\mathbf{T}$ & $\mathbf{R}$ & $\mathbf{A}$ & $\mathbf{D}$ & $\mathbf{T}$ & $\mathbf{R}$ & $\mathbf{A}$ & $\mathbf{D}$ & T & $\mathbf{R}$ & $\mathbf{A}$ & $\mathbf{D}$ \\
\hline $\mathbf{3 5 0}$ & $\mathbf{0 . 3 2 3}$ & $\mathbf{0 . 0 4 7}$ & $\mathbf{0 . 6 3 0}$ & $\mathbf{0 . 2 7 4}$ & $\mathbf{0 . 3 0 9}$ & $\mathbf{0 . 0 4 5}$ & $\mathbf{0 . 6 4 6}$ & $\mathbf{0 . 2 8 1}$ & $\mathbf{0 . 3 8 9}$ & $\mathbf{0 . 0 4 4}$ & $\mathbf{0 . 5 6 7}$ & $\mathbf{0 . 2 4 6}$ \\
\hline $\mathbf{4 0 0}$ & $\mathbf{0 . 4 7 4}$ & $\mathbf{0 . 0 4 6}$ & $\mathbf{0 . 4 8 0}$ & $\mathbf{0 . 2 0 8}$ & $\mathbf{0 . 4 4 6}$ & $\mathbf{0 . 0 4 4}$ & $\mathbf{0 . 5 1 0}$ & $\mathbf{0 . 2 2 2}$ & $\mathbf{0 . 5 8 8}$ & $\mathbf{0 . 0 4 5}$ & $\mathbf{0 . 3 6 7}$ & $\mathbf{0 . 1 5 9}$ \\
\hline $\mathbf{4 5 0}$ & $\mathbf{0 . 7 3 5}$ & $\mathbf{0 . 0 4 5}$ & $\mathbf{0 . 2 2 0}$ & $\mathbf{0 . 0 9 6}$ & $\mathbf{0 . 7 0 6}$ & $\mathbf{0 . 0 4 3}$ & $\mathbf{0 . 2 5 1}$ & $\mathbf{0 . 1 0 9}$ & $\mathbf{0 . 7 8 7}$ & $\mathbf{0 . 0 4 2}$ & $\mathbf{0 . 1 7 1}$ & $\mathbf{0 . 0 7 4}$ \\
\hline $\mathbf{5 0 0}$ & $\mathbf{0 . 7 5 6}$ & $\mathbf{0 . 0 4 4}$ & $\mathbf{0 . 2 0 0}$ & $\mathbf{0 . 0 8 7}$ & $\mathbf{0 . 7 3 7}$ & $\mathbf{0 . 0 4 2}$ & $\mathbf{0 . 2 2 1}$ & $\mathbf{0 . 0 9 6}$ & $\mathbf{0 . 7 8 9}$ & $\mathbf{0 . 0 4 3}$ & $\mathbf{0 . 1 6 8}$ & $\mathbf{0 . 0 7 3}$ \\
\hline
\end{tabular}

Table 2:- Values of the transmittance, $\boldsymbol{T}$, reflectance, $\boldsymbol{R}$, absorbance, $\boldsymbol{A}$ and optical density, $\boldsymbol{D}$ obtained from the optical spectrum at $\lambda=630 \mathrm{~nm}$ for electrochromic behaviour of $\mathrm{IrO}_{2}$ as a function of solution molarity.

\begin{tabular}{|c|c|c|c|c|c|c|c|c|c|c|c|c|}
\hline \multirow{2}{*}{$\begin{array}{l}\text { Solution } \\
\text { molarity } \\
\text { (SM) }\end{array}$} & \multicolumn{4}{|c|}{ As-deposited [15] } & \multicolumn{4}{|c|}{ Coloured state } & \multicolumn{4}{|c|}{ Bleached state } \\
\hline & $\mathbf{T}$ & $\mathbf{R}$ & $\mathbf{A}$ & D & $\mathbf{T}$ & $\mathbf{R}$ & $\mathbf{A}$ & D & $\mathbf{T}$ & $\mathbf{R}$ & $\mathbf{A}$ & D \\
\hline 0.005 & 0.735 & 0.062 & 0.203 & 0.088 & 0.703 & $\begin{array}{l}\text { 0 } \\
.058\end{array}$ & 0.239 & 0.104 & 0.769 & 0.066 & 0.180 & 0.078 \\
\hline 0.01 & 0.580 & 0.038 & 0.382 & 0.166 & 0.562 & 0.040 & 0.398 & 0.173 & 0.659 & 0.044 & 0.313 & 0.136 \\
\hline 0.02 & 0.485 & 0.046 & 0.469 & 0.204 & 0.472 & 0.044 & 0.484 & 0.210 & 0.557 & 0.049 & 0.397 & 0.172 \\
\hline 0.03 & 0.458 & 0.058 & 0.484 & 0.210 & 0.452 & 0.060 & 0.488 & 0.212 & 0.528 & 0.061 & 0.414 & 0.179 \\
\hline
\end{tabular}

Table 3:- The experimental data of electrochromic characteristics for $\mathrm{IrO}_{2}$ thin films as a function of substrate temperature.

\begin{tabular}{|c|c|c|c|c|c|c|}
\hline $\mathrm{T}_{\text {sub }}\left({ }^{\circ} \mathrm{C}\right)$ & $\begin{array}{l}T_{b} \\
(\lambda=630 \mathrm{~nm})\end{array}$ & $\begin{array}{l}T_{c} \\
(\lambda=630 \mathrm{~nm})\end{array}$ & $\begin{array}{l}Q_{i} \\
\left(\mathbf{m C} / \mathrm{cm}^{2}\right)\end{array}$ & $\begin{array}{l}\text { Photopic ratio } \\
\left(\mathbf{T}_{b} / \mathbf{T}_{c}\right)\end{array}$ & $\Delta O D$ & $\begin{array}{l}\mathrm{CE} \\
\left(\mathrm{cm}^{2} / \mathrm{C}\right)\end{array}$ \\
\hline 350 & $\mathbf{3 8 . 8 5 2}$ & 30.885 & 11.625 & 1.258 & 0.229 & 19.744 \\
\hline 400 & 58.756 & 644.586 & 8.534 & 1.318 & 0.276 & 32.355 \\
\hline 450 & 78.684 & 470.634 & 6.442 & 1.114 & 0.108 & 16.758 \\
\hline 500 & 78.863 & 73.687 & 4.514 & 1.070 & 0.068 & 14.988 \\
\hline
\end{tabular}

Table 4:- The experimental data of electrochromic characteristics for $\mathrm{IrO}_{2}$ thin films as a function of solution molarity.

\begin{tabular}{|l|l|l|l|l|l|l|}
\hline $\begin{array}{l}\text { Solution } \\
\text { molarity }(\mathbf{M})\end{array}$ & $\begin{array}{l}\mathbf{T}_{\mathbf{b}} \\
(\lambda=630 \mathrm{~nm})\end{array}$ & $\mathbf{T}_{\mathbf{c}}(\lambda=630 \mathrm{~nm})$ & $\begin{array}{l}\mathbf{Q}_{\mathrm{i}} \\
\left(\mathbf{m C}_{\mathbf{c}} \mathbf{c m}^{2}\right)\end{array}$ & $\begin{array}{l}\text { Photopic ratio } \\
\left(\mathbf{T}_{\mathbf{b}} / \mathbf{T}_{\mathbf{c}}\right)\end{array}$ & $\mathbf{O D} \Delta$ & $\begin{array}{l}\mathbf{C E} \\
\left(\mathbf{c m}^{2} / \mathbf{C}\right)\end{array}$ \\
\hline $\mathbf{0 . 0 0 5}$ & $\mathbf{7 6 . 8 6 3}$ & $\mathbf{7 0 . 2 5 4}$ & $\mathbf{5 . 5 1 3}$ & 1.094 & $\mathbf{0 . 0 8 9}$ & $\mathbf{1 6 . 2 9 6}$ \\
\hline $\mathbf{0 . 0 1}$ & $\mathbf{6 5 . 8 9 2}$ & $\mathbf{5 6 . 1 8 5}$ & $\mathbf{7 . 6 2 4}$ & $\mathbf{1 . 1 7 3}$ & $\mathbf{0 . 1 5 9}$ & $\mathbf{2 0 . 9 2 9}$ \\
\hline $\mathbf{0 . 0 2}$ & $\mathbf{5 5 . 6 8 4}$ & $\mathbf{4 7 . 2 1 4}$ & $\mathbf{1 2 . 5 1 5}$ & $\mathbf{1 . 1 7 9}$ & $\mathbf{0 . 1 6 5}$ & $\mathbf{1 3 . 1 5 6}$ \\
\hline $\mathbf{0 . 0 3}$ & $\mathbf{5 2 . 7 5 2}$ & $\mathbf{4 5 . 2 3 3}$ & $\mathbf{1 5 . 2 2 3}$ & $\mathbf{1 . 1 6 6}$ & $\mathbf{0 . 1 5 4}$ & $\mathbf{1 0 . 0 0 9}$ \\
\hline
\end{tabular}




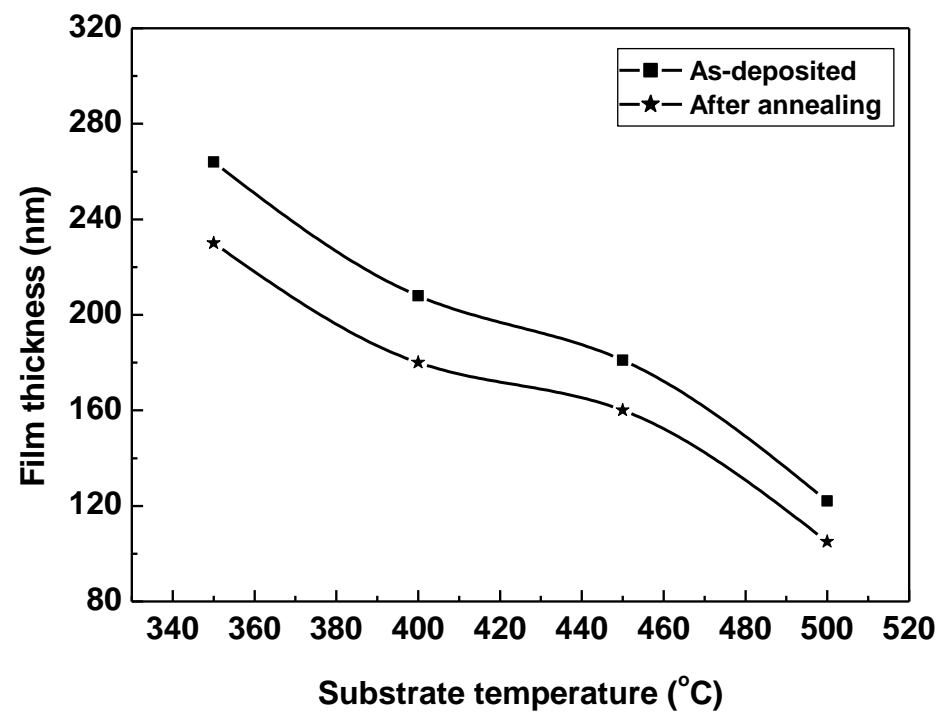

Fig. ( 1 ):- Variation of Ir-oxide film thickness with substrate temperature for as-deposited and annealed films.

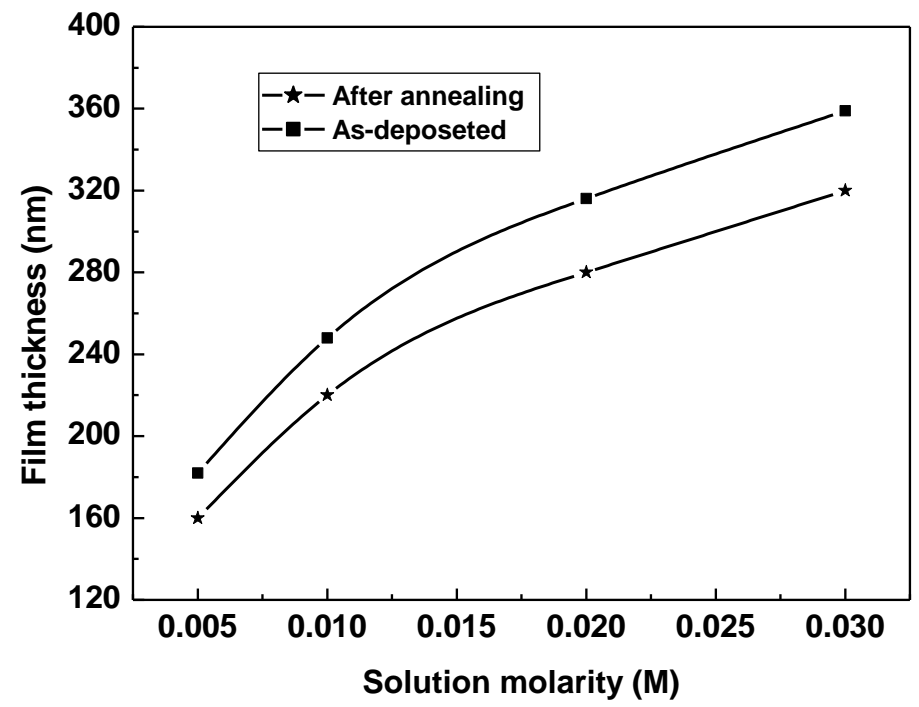

Fig. ( 2 ):- Variation of Ir-oxide film thickness with solution molarity for as-deposited and annealed films 

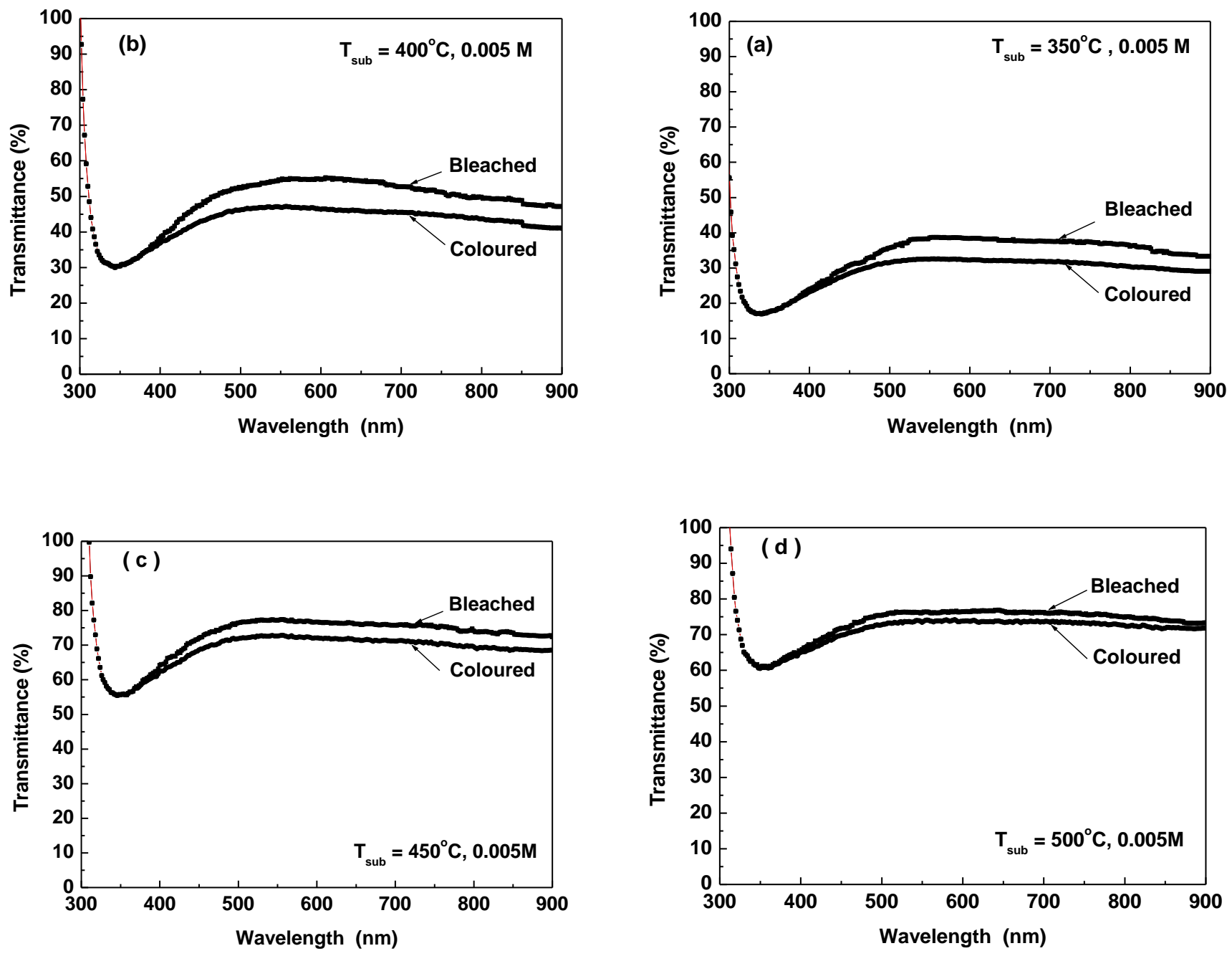

Fig.(3):- Optical transmittance spectra recorded in the coloured (C) and bleached (B) states at different substrate temperature; (a) $350^{\circ} \mathrm{C}$, (b) $400^{\circ} \mathrm{C}$, (c) $450^{\circ} \mathrm{C}$ and (d) $500^{\circ} \mathrm{C}$.
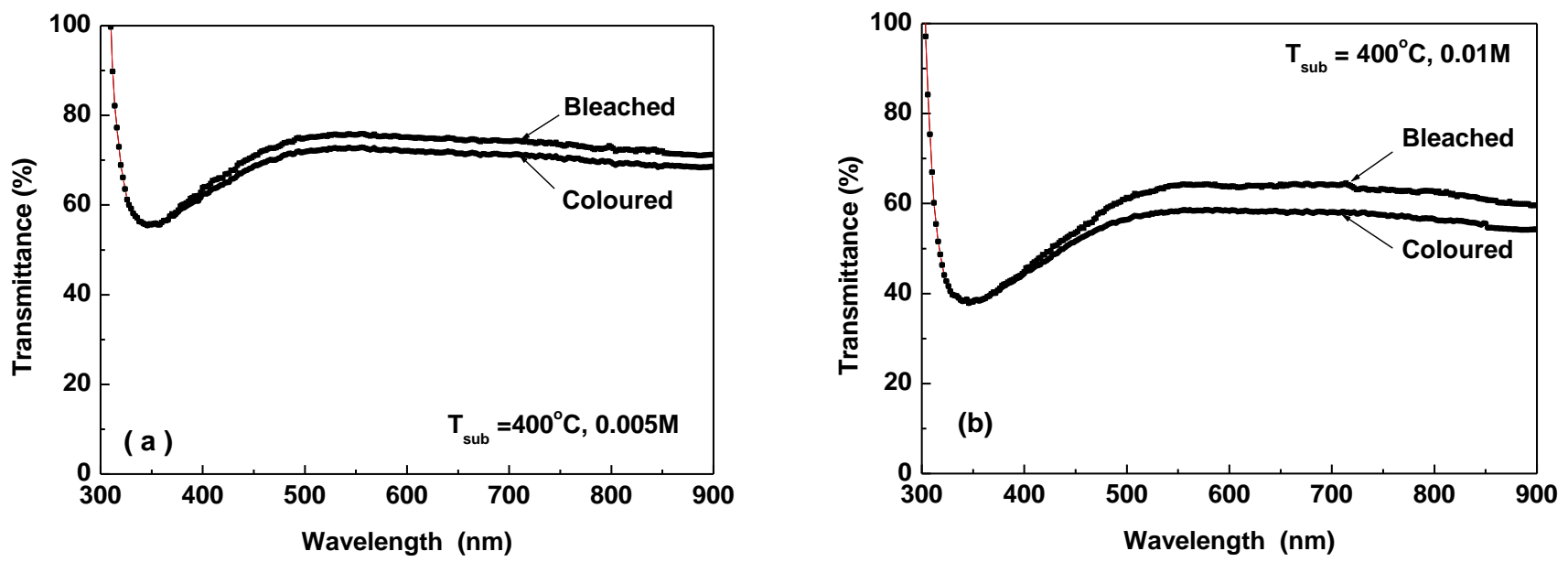

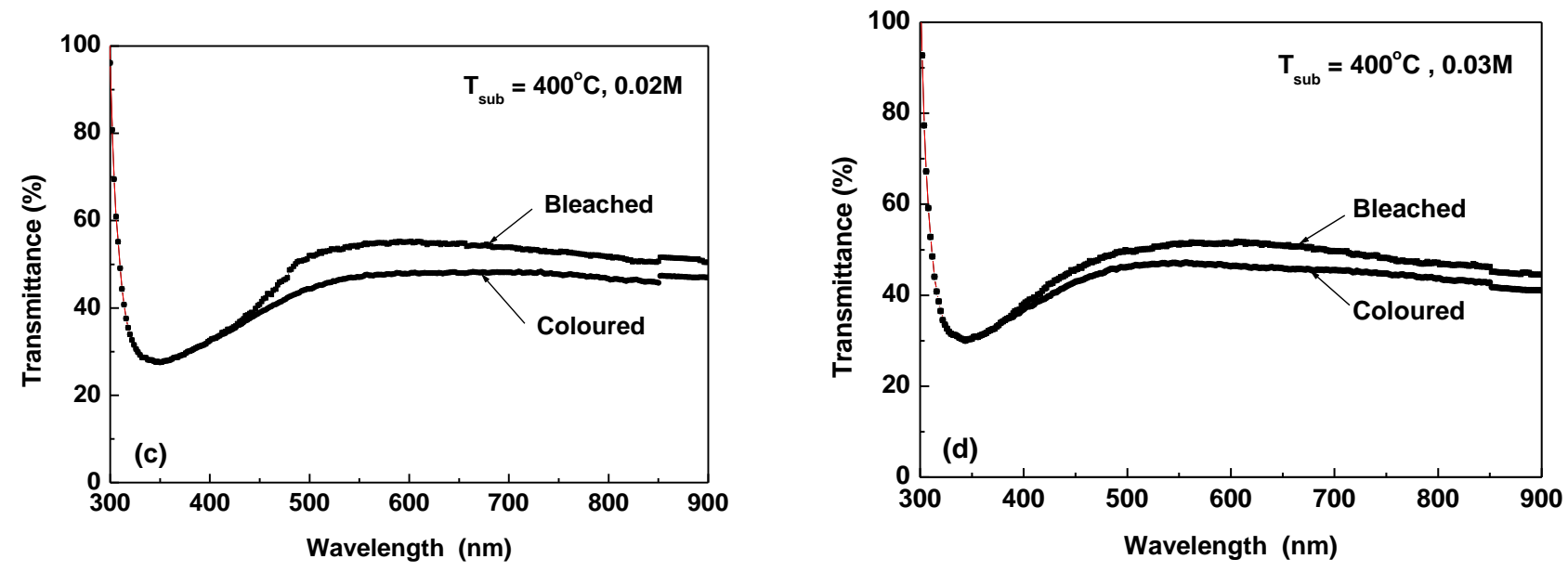

Fig. (4)

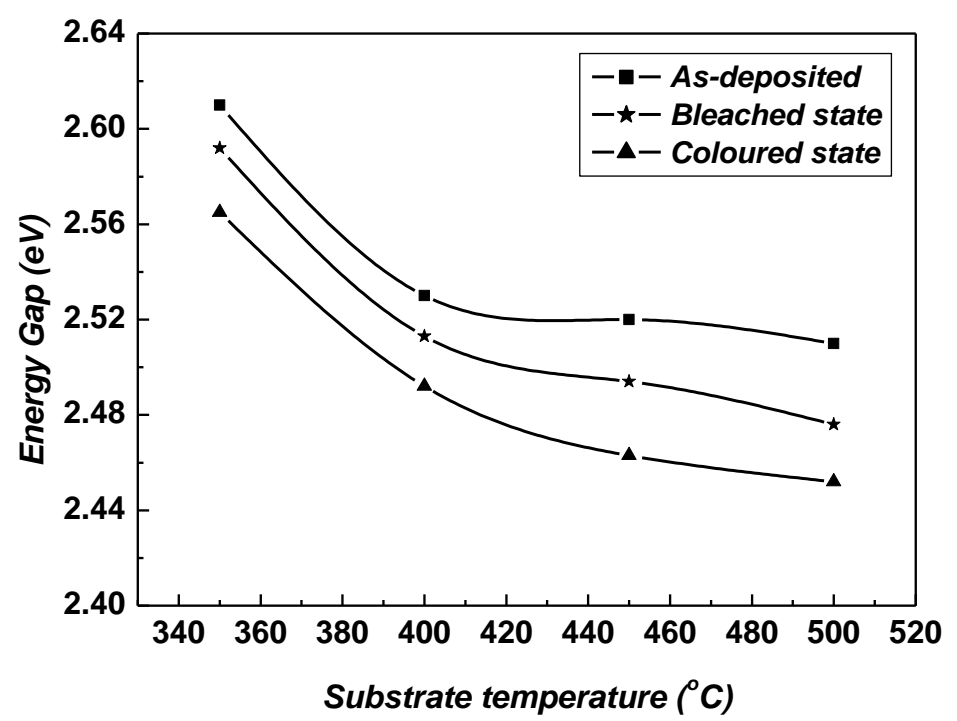

Fig. ( 5 ):- Optical transmittance spectra recorded in the coloured (C) and bleached (B) states at different solution molarity; (a) $0.005 \mathrm{M}$, (b) $0.01 \mathrm{M}$ (c) $0.02 \mathrm{M}$ and (d) $0.03 \mathrm{M}$ 


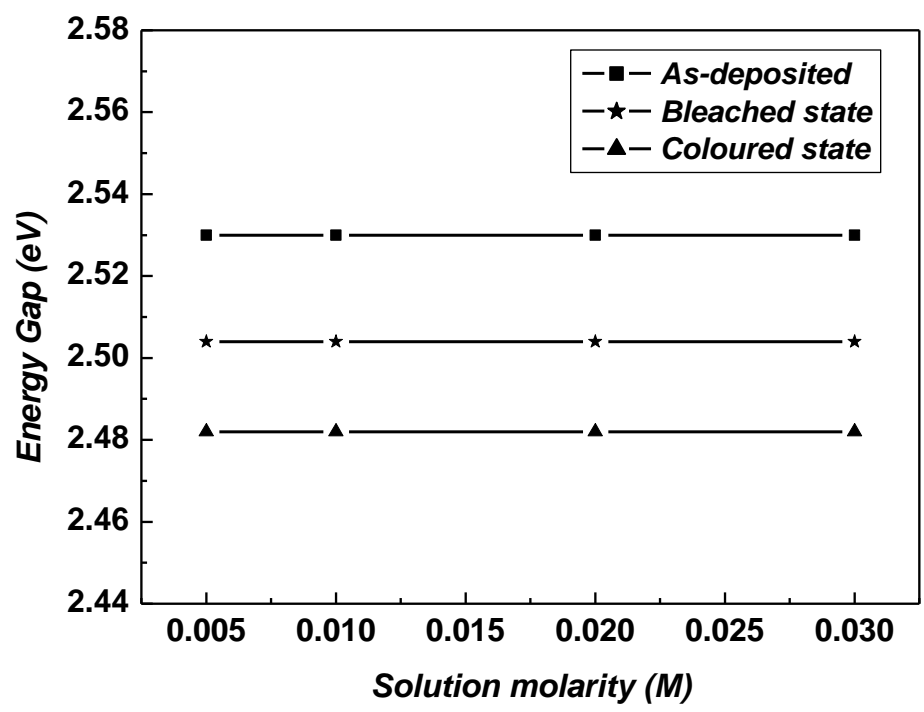

Fig. ( 6 ):- Variation of the energy gap with solution molarity for as-deposited, bleached and coloured state.

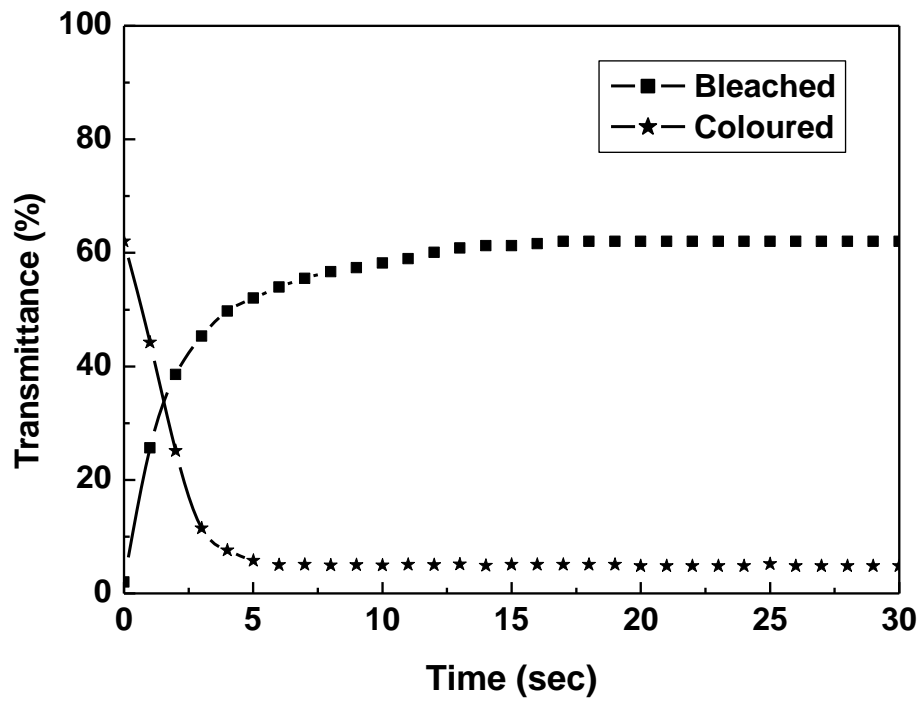

Fig. ( 7 ):- Time variations of the transmittance measured at 630nm of colour-bleached state. 


\section{References:-}

1. C.G. Granqvist, Handbook of Inorganic Electrochromic Materials, Elsevier, Amsterdam, (1995)225.

2. P.M.S. Monk, R.J. Mortimer, D.R. Rosseinsky, Electrochromism: Fundamentals and Applications, VCH, Weinheim, (1995).

3. P.S.Patil, S.H.Mujwar, S.B.Sadale, H.P.Deshmukh, A.I.Inamdar; Materials Chemistry and Physics 99 (2006) 309.

4. S.H. Lee, S.K. Joo, Solar Energy Materials and Solar Cells 39 (1995) 155.

5. D.N. Buckley, L.D. Burke, J. Chem. Soc. Faraday Trans. 1 (1976)2431.

6. G. Beni, J.L. Shay, Appl. Phys. Lett. 33 (1978) 567.

7. S. Gottesfeld, J.D.E. Mcintyre, G. Beni, J.L. Shay, Phys. Lett. 33 (1978) 208.

8. Y. Sato, Vacuum 41 (1990) 1178.

9. K. Yamanaka, Jpn. J. Appl. Phys. 30 (1991) 1285.

10. S. Hackwood, A.H. Dayen, G. Beni, Phys. Rev. (B) 26 (1982) 471.

11. K. Yamanaka, Jpn. J. Appl. Phys. 28 (1989) 632.

12. Y. Takasu, S. Onone, K. Kameyama, Y. Murakami, Y. Kozawa, Electrochimica Acta 39 (1994) 1993.

13. P.S. Patil, R.K. Kawar, S.B. Sadale, Applied Surface Science 249 (2005) 367.

14. A.A.Akl and S.A.Mahmoud, The Arabian Journal for Science and Engineering, (AJSE), xxx (2009) xxx.

15. S.A. Mahmoud,_, A.A. Akl S.M. Al-Shomar, Physica B 404 (2009) 2151.

16. S.A. Mahmoud, Solid State Science 4 (2002) 221.

17. P.S.Patil, P.S.Chigare, S.B.Sadale, T.Seth, D.P.Amalnerkar, R.K.Kawar; Materials Chemistry and Physics 80 (2003) 667.

18. T. Sameshima, K. Saitoh, N. Aoyama, S. Higashi, M. Kondo, A. Matsuda, Jpn. J. Appl. Phys. 38 (1999) 1892.

19. C. Das, S. Ray, Thin Solid Films 403-404 (2002) 81.

20. R.K. Kawar, P.S. Chigare, P.S. Patil, Applied Surface Science 206 (2003) 90.

21. P.S.Patil, R.K.Kawar, S.B.Sadale; Electrochimica Acta 50 (2005) 2527.

22. P.S.Patil, S.H.Mujawar, S.B.Sadale, H.P.Deshmukh, A.I.Inamdar, Materials Chemistry and Physics 99 (2006) 309.

23. P.S. Patil, R.K. Kawar, S.B. Sadale, A.I. Inamdar, S.S. Mahajan, Solar Energy Materials \& Solar Cells ,90 (2006) 1629.

24. P.W. Atkins, Physical Chemistry, Oxford University Press, (1994)545.

25. B.P. Asthana, W. Kiefer, Appl. Spectrosc., 36 (1982) 250.

26. N.F.Mott and E.A.Davis, ' Electronic Process in Non-Crystalline Materials", Clarendon Press, Oxford, (1979).

27. M.Cardona, Phys. Status. Solidi, A 188, 1209 (2001).

28. B.Bansal, V.K.Dixit, V.Venkataraman and H.L.Bhat; Applied Physics Letters, 82 (26) (2003) 4720. 